\title{
Promoting Cities: Measures to Improve Urban Marketing Strategy
}

\author{
Ruxandra Irina POPESCU1 \\ Laura MINA-RAIU²
}

\begin{abstract}
This study aims to identify the perception of residents and tourists related to the current practices and the level of promotion of Bucharest, as well as to reveal ways and opportunities to improve the effectiveness of this activity. Data collection for this research is based on a survey, whose main findings reveal that Bucharest lacks an appropriate promoting strategy and a strong urban brand. Moreover, public authorities are the ones who should initiate activities for promoting the city, by developing a complex and long-term urban marketing strategy. Instead, private initiatives prove to be the most successful, thus public-private partnerships could be an effective instrument in this direction, together with the establishment of a specialised marketing department.
\end{abstract}

KEYWORDS: Promotion, Urban Marketing, Strategy.

JEL CLASSIFICATION: $M 37,018$

\section{INTRODUCTION}

In order to attract potential investors as well as tourists, the city has to be seen as a commercial product, using sales techniques and principles, in order to be ,sold”. In order to "sell" a city, there is a need for a development strategy that contains general and specific objectives to make it possible to position the city and draw the main directions of action.

The paper focuses on Bucharest, the capital city of Romania from the perspective of tourism promotion current situation. Although the concept of urban marketing is relatively new in Romania, it can be noticed that there are attempts to implement it.

The most important part of this paper is the research itself that reveals the strengths and weaknesses of Bucharest, as well as the ways to improve the city's appearance, the necessary measures to solve the problems faced by the capital and identifies elements and symbols that can build a strong and unique urban brand. In order to "sell" the capital of Romania, we need to present it in a proper, "packaged" manner to attract as many visitors as possible.

The creation of a competitive capital city is closely related to its problems regarding transport infrastructure, quality of public services, general aesthetics (state of buildings and monuments, sanitation). We have discovered that some locations, should be at the heart of measures to improve its marketing strategy.

\section{LITERATURE REVIEW}

Urban marketing is an indispensable element for city development strategies, contributing to the overall vision of the strategy (Kotler, 2001). This helps cities achieve more goals (attracting new national or international companies, strengthening industrial infrastructure, developing tourism, diversifying and improving transport and health services), while they must keep under

\footnotetext{
${ }^{1}$ Bucharest University of Economic Studies, Romania, irina.popescu@man.ase.ro (the corresponding author)

${ }^{2}$ Bucharest University of Economic Studies, Romania, laura.minaraiu@amp.ase.ro
} 
control or diminish public spending and face tough competition to attract new investors. The biggest challenges for urban marketing are the changes in the structure and dynamics of the market, which surpass the cities' ability to respond (Ave and Corsico, 1994; Constantinides, 2006).

The mere existence of well-established industrial infrastructure is not enough to make a community meet its development goals. That is why marketing must create the image, or rather, the message to be sent to potential investors. Urban marketing involves choosing appropriate ways of designing and organizing cities to meet the needs of the target segments interested in urban development (Dril et al., 2016). It is considered that urban marketing has reached its goal when the community of businessmen and citizens are satisfied with the economic and social environment, when the expectations of visitors and investors are met (Kotler et.al, 2002).

The literature in this field focuses on emphasizing the importance of developing cities and constantly promoting its elements, increasing competitiveness as an indirect effect of applied strategies. Urban marketing must be conceived as a general principle, focused on city development, for example, on issues related to housing, jobs, communications, facilities and environment. It is also characterized by a planning process that includes all the steps of assigning tasks, the current situation, analysing strengths and weaknesses, defining its level of competitiveness and implementing, monitoring and evaluating activities (Avraham, 2009).

Extending the urbanization process has led to the unanimous acceptance of the urban marketing concept. Additionally, the acceptance of this concept has also been achieved because of competition between cities, a competition to attract more tourists, residents and potential investors to raise the standard of living in cities. Thus, the city is seen as a product to be exploited to ensure its survival and development.

Several authors believe that cities have become the most dynamic centres of change in the global economy (Harris, 1997; Harvey, 2012), while other specialists consider that high competition between major cities is caused by the construction of the international economy, while for small towns the entry into competition is a requirement to survive (Friedrichs and Dangschat, 1994; Turok and Mykhnenko, 2007). A key element in urban marketing is the difficulty of defining the identity and values of the city in a way that can be widely accepted and easily marketed for all target groups (Kiseleva, 2017).

The challenge is the need to create a common identity from values that are not always tangible and represent the interests of different social and economic groups (Wensley, 2016). Urbanism must determine how culture, history, economic growth, social development, infrastructure, architecture, the landscape and the environment, among other components, can be combined into an identity that can be later capitalized (Zhang, 2009). In this process, the role of decisionmakers is crucial and, in order for urban marketing to succeed, a long-term vision is needed, both in terms of marketing and management (Eshuis et al., 2014).

Economic development has always been a priority for cities, regions and states, but in the last decade they have decided to change the perspective, from a narrow perspective of economic progress, to a wider strategy to attract new companies and maintain those already present, the development of international trade and tourism and the attraction of new investors (Kotler, 2001).

States, regions, and cities have transformed their circumstantial economic campaigns into complex marketing strategies that aim to create competitive markets, guide potential buyers, 
and distribute community resources, responding to the needs and expectations of expert consumers (Wu, 2016).

Public authorities changed their thinking, focusing on the client, not on the product, and promoting co-operation against strict bureaucratic rules. In addition, communication must not be intrinsic to the organization, and local government must have autonomy in making decisions. The citizen-user has turned into the citizen-client. It is intended to meet the needs of "the city's client", as his approval ensures the success of urban marketing activities. Citizens or interest groups can intervene in making decisions, so authorities need to ensure full expression of customer preferences and wishes, adopt new methods of communication that help them understand and find new forms of intervention.

A conscious enterprise emerges from the inclusion of private firms in the development process of the urban development strategy. Their participation provides a different field of action, requiring a broader set of objectives and acceptance of different models by those in competition.

\section{RESEARCH METHODOLOGY}

The main goal of this research is to identify the level of promotion of Bucharest, as well as to reveal ways and opportunities to improve this activity. In order to reach this goal, four research objectives and four hypotheses were defined:

Objective 1: Identify the current situation in the Romanian capital in the field of marketing and urban branding.

Objective 2: Identify opportunities that can help promote the city and, implicitly, create a strong urban brand.

Objective 3: Identify the contribution of local authorities and the private sector in promoting the city.

Objective 4: Identify respondents' perception on the overall image of the capital city.

The assumptions on which the present research is based are:

Hypothesis 1: The City of Bucharest is being promoted in an appropriate way.

Hypothesis 2: Developing a marketing strategy and setting up a department within the Bucharest Municipality with the mission to carry out activities aimed at increasing the attractiveness of the city is necessary for an effective promotion.

Hypothesis 3: In order to improve the activity of promoting the city and increasing the attractiveness, it is necessary to organize a larger number of sports, cultural, musical events in the public sector and to attract events that are known at global or European level.

Hypothesis 4: Bucharest does not have a strong urban brand, and improvements are needed.

The research tool used in this study is a questionnaire that consists of 18 closed questions, divided into two sections:

- the first part consists in identification questions that facilitate the classification of respondents according to several criteria, such as gender, age, recent activity, level of education and residence area. Thus, most respondents' age is between 36-45 years old (32\%), followed by $46-55$ years old (22\%), 26-35 years old ( $25 \%), 18-25$ years old $(15 \%)$, $56-65$ years old $(9 \%)$ and $6 \%$ are over 66 years old. In terms of gender, $47 \%$ of the respondents are men and 53\% women.

According to the level of studies $58 \%$ are higher education graduates (bachelor degree, master degree, $\mathrm{PhD}$, postdoctoral), $18 \%$ hold a post-secondary school degree and $22 \%$ have 
a high school degree. $66 \%$ of respondents are employed, $8 \%$ of respondents are retired, $24 \%$ are pupils or students, and $2 \%$ are unemployed.

In the sample selected for research we chose to include both Bucharest residents and domestic and foreign tourists who were in the capital city at the time of the data collection activity. Thus, $82 \%$ of respondents are the inhabitants of Bucharest, and $18 \%$ are tourists (domestic or foreign).

- the second part of the questionnaire was elaborated in order to test our hypotheses. Through the questions, we wanted to find out if respondents are aware of the ways Bucharest is promoted, if this activity requires improvements and city-related issues that cause discontent among citizens and tourists. In addition, we wanted to make a top of the main buildings that respondents considered to be emblematic for the city, identifying the elements by which Bucharest differs from other European cities and the activities that the respondents have participated in lately.

For data collection, we used the online questionnaire (disseminated through social networks, email, phone applications) as well as face to face data collection. A total of 384 questionnaires were collected and analysed in April-May 2017, using Microsoft Office Excel and E-Views software.

\section{RESEARCH RESULTS}

This section of the paper is aimed at revealing the most relevant survey findings that test the above mentioned hypothesis. Regarding respondents' familiarity with the ways through which the city of Bucharest is being promoted, results show that $58 \%$ of respondents are aware of the ways in which the city is promoted, while $38 \%$ are not aware of the promotion methods (see Figure 1).

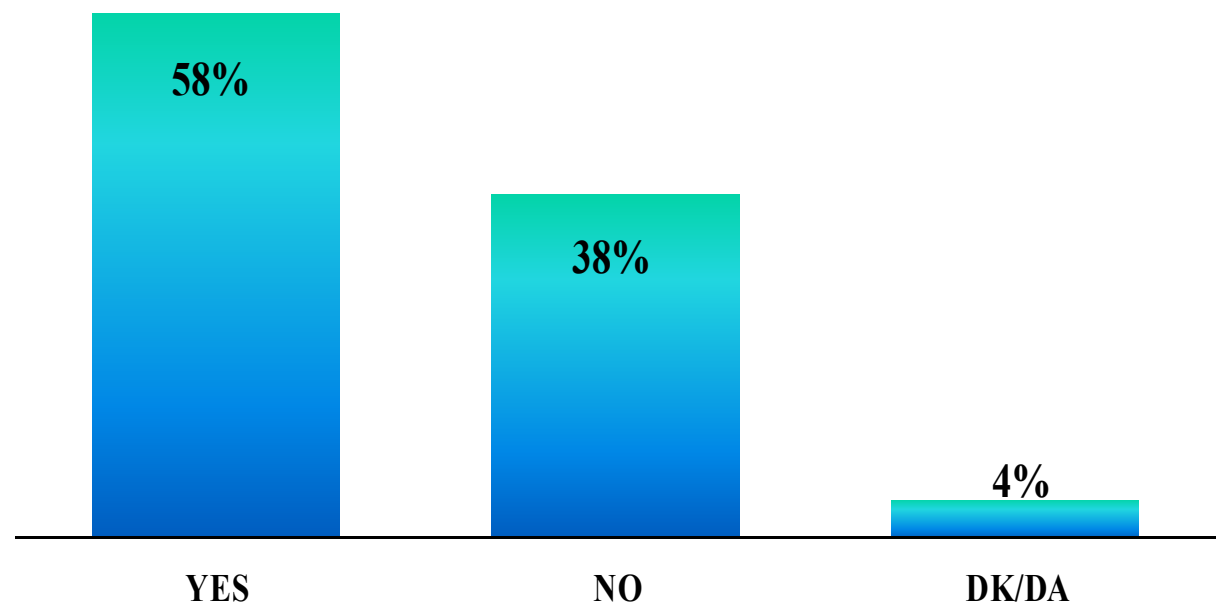

Figure 1. Awareness of city promotion ways Source: Authors, based on collected data

Regarding the need to improve the way the capital city is promoted, $81 \%$ of respondents argued that improvement measures are needed to increase the attractiveness of the city, $12 \%$ said they are satisfied with the way the city is being promoted and $8 \%$ of respondents did not answer this question (see Figure 2). 


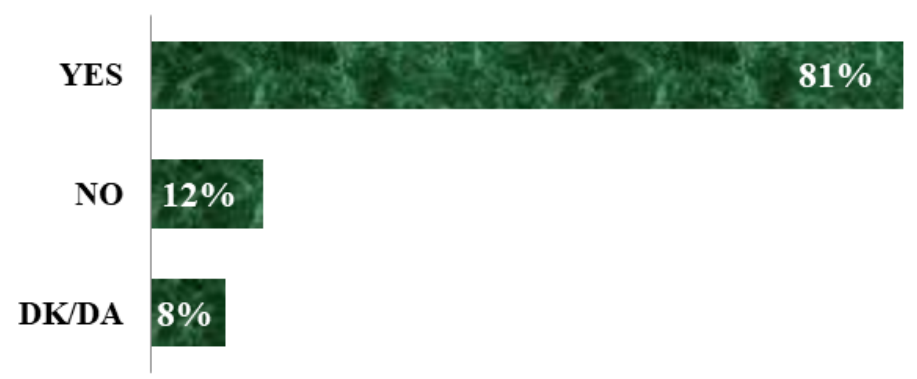

Figure 2. Need to improve city promotion Source: Authors, based on collected data

When referring to the causes underlying the low performance levels of promotional activities (Figure 3), the negligent aspect of the capital city which leads to a decrease in the number of tourists was pointed out in $59 \%$ of responses. The same percentage goes to the lack of a city marketing strategy. The next issue is the poor quality of public services $(52 \%)$ and the lack of an urban brand (35\%). We can assume that the lack of a consolidated marketing strategy is the main cause of poor promotion, followed by the negligent aspect of the capital that leads to the formation of a negative image of the city and the creation of preconceived ideas that may be difficult to remove.

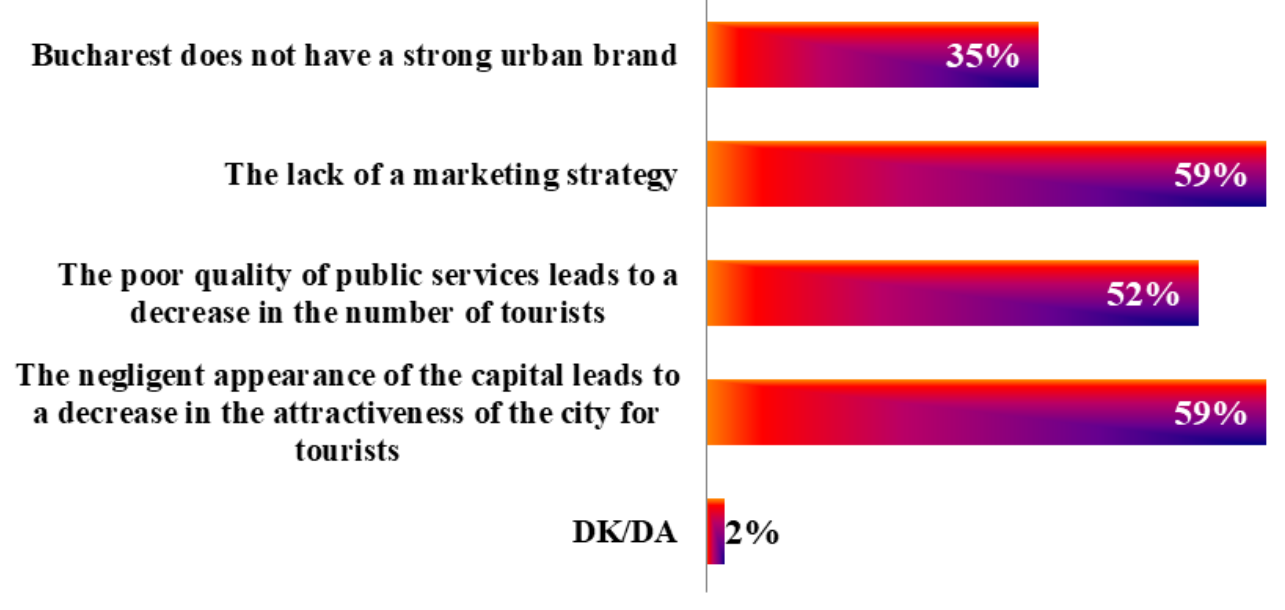

Figure 3. Causes for poor promotion of the city

Source: Authors, based on collected data

In order to have a strong brand, but also to achieve efficient and effective promotion, awareness of the elements that distinguish the city from other cities in Europe or in the world is crucial, together with the knowledge of the emblematic elements of the city (Figure 4). Thus, respondents' perception on the elements that lead to the differentiation between Bucharest and other cities point out: lifestyle (38\%), architecture $(34 \%)$, particular historical load $(26 \%)$. We consider that all these three elements are indeed emblematic, however the architectural style of the city is the one that can be exploited much more effectively. 




Figure 4. Bucharest versus other European cities Source: Authors, based on collected data

The survey findings reach a top of the five most emblematic buildings in the capital of Romania (Figure 5). First in this top is the Parliament Palace (74\%), followed by the Arch of Triumph (49\%), Romanian Athenaeum (45\%) and the National Theatre (23\%). The Romanian Opera and the Intercontinental Hotel share the same position $(19 \%)$ and at the bottom of the ranking there are the CEC Palace (15\%) and Stavropoleos Church (9\%). Thus, based on the responses, we can assume that the city's emblems are the Parliament Palace (probably because it is the largest building in Europe and the second largest administrative building in the world, the most expensive administrative building in the world and the heaviest building in the world), the Arch of Triumph and the Romanian Athenaeum.

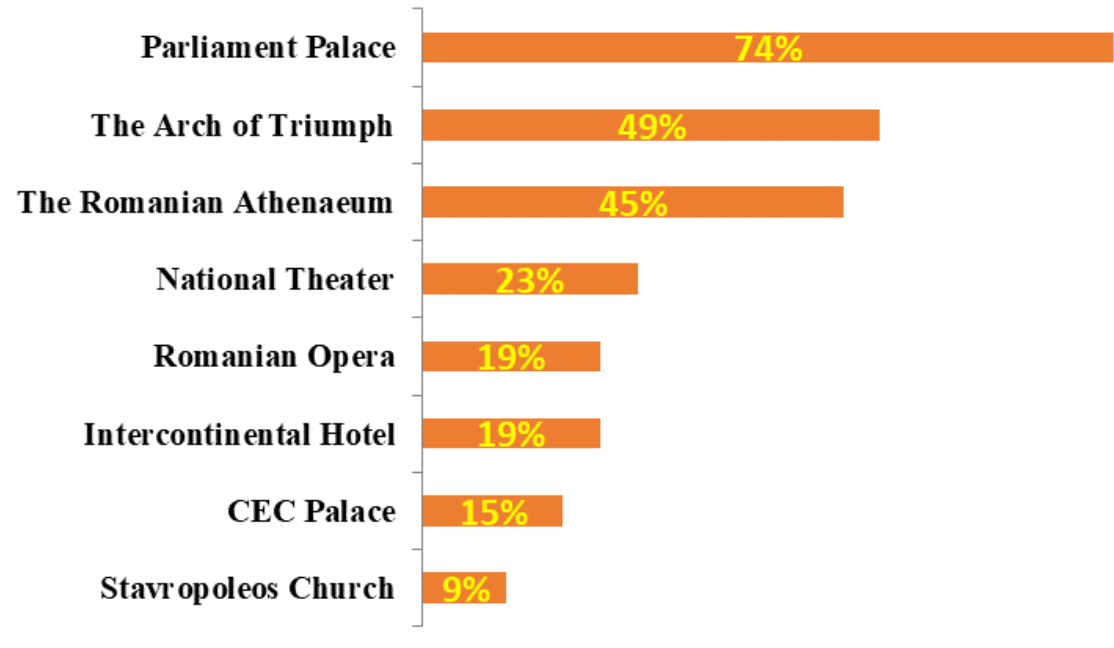

Figure 5. Symbols of Bucharest

Source: Authors, based on collected data

From the perspective of the elements that may be used to design a strong urban brand for the city of Bucharest, $23 \%$ of the respondents suggested the creation of several recreation and entertainment areas, 55\% indicated the need for high quality public services, $67 \%$ consider developing infrastructure would support efforts to build a positive image, $59 \%$ believe that promoting the main tourist attractions will lead to developing of an urban brand, and $18 \%$ consider that a unique image is needed to have an urban brand (Figure 6). Thus, creating a city brand requires a unique image and, of course, promoting the main symbols and assets of the city. 


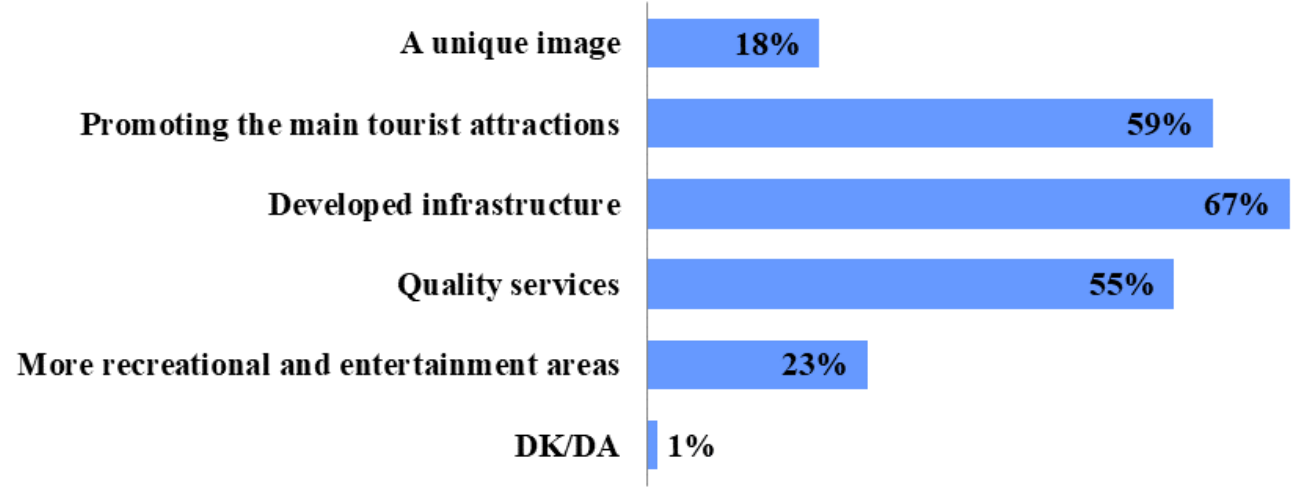

Figure 6. Elements necessary for building a strong urban brand for Bucharest Source: Authors, based on collected data

It is well known that running important events of any kind, known at European or global level, may lead to an increase in the number of tourists willing to travel and participate in those activities. Through the questionnaire applied in the research we aimed to find out precisely this, namely the respondents' opinion about the relationship between the organization of the various events and the number of persons attracted by them. Thus, $80 \%$ of the subjects believe that the organization of such events results in higher numbers of tourists, both domestic and foreign. Only $6 \%$ consider that there is no direct relationship between them, and 15\% refrained from answering this question (Figure 7).

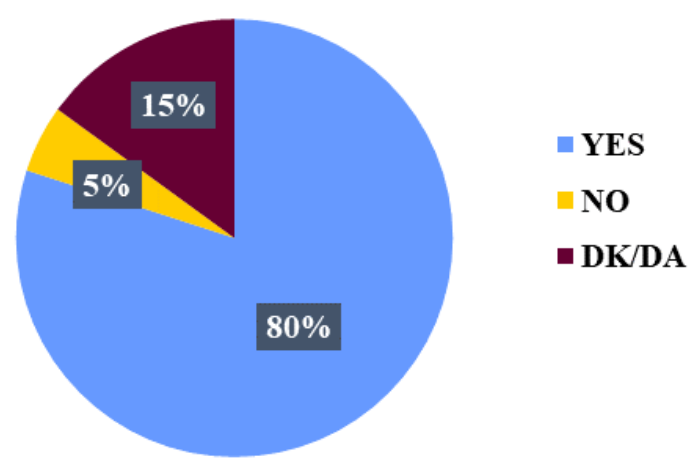

Figure 7. The importance of attracting more events in Bucharest

Source: Authors, based on collected data

Even if various events are organized in the city, citizens need to be informed and become interested in them. That is why we wanted to find out what kind of events, organized in Bucharest, have respondents attended in the last period. In the top of their preferences there are cultural events (42\%), followed by musical festivals $(38 \%)$, sports events $(28 \%)$, art exhibitions (20\%) and gastronomic festivals (19\%). 6\% of respondents said they have not attended any event lately (Figure 8). 


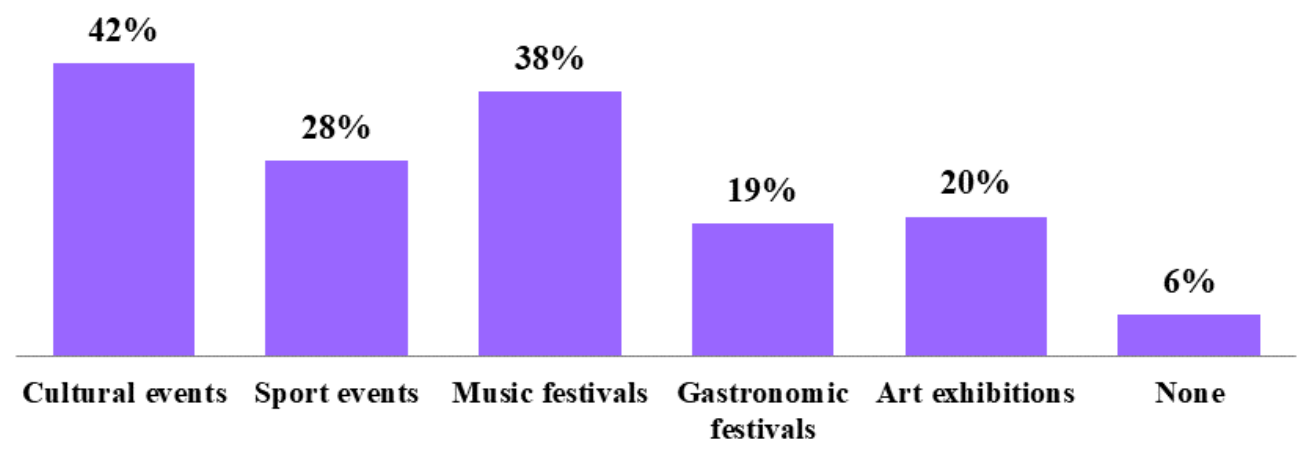

Figure 8. Events attended by respondents Source: Authors, based on collected data

Regarding the involvement of local authorities in the promotion of Bucharest, $87 \%$ respondents argued that they did not get involved sufficiently, and that a better involvement through different approaches is needed. $8 \%$, a fairly small percentage, said that Bucharest is being promoted in an efficient way, with no need for improvement, and $5 \%$ of respondents did not answer this question (Figure 9). Surely local authorities' efforts in promoting Bucharest can be improved because the city enjoys many opportunities that need to be taken advantage of in order to create a strong competitive image.

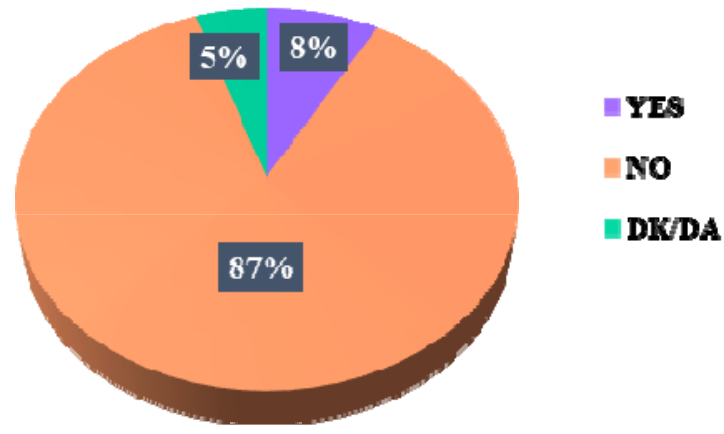

Figure 9. Involvement of local authorities Source: Authors, based on collected data



Figure 10. Involvement of the private sector in promoting Bucharest through advertising campaigns Source: Authors, based on collected data 
On the other hand, $48 \%$ of respondents consider that in terms of advertising campaigns the private sector is more involved in promoting the city by comparison to local authorities (Figure 10), which is consistent with the finding from the literature review.

In order to observe the impact of the city's promotional campaigns and in addition to see if they were effectively delivered to the population, we selected four promotion campaigns and asked survey subjects whether they were familiar with them. $67 \%$ of the respondents knew about the Light Festival, 13\% said they held information about the Cultural Strategy of the Capital and promoting the capital through the new \#SEEBUCHAREST site and only 5\% were aware of \#EXPPERIENCEBUCHAREST, the project initiated by young volunteers and influential people in tourism. 14\% of the research participants said they have not heard of any of previously mentioned events (Figure 11).

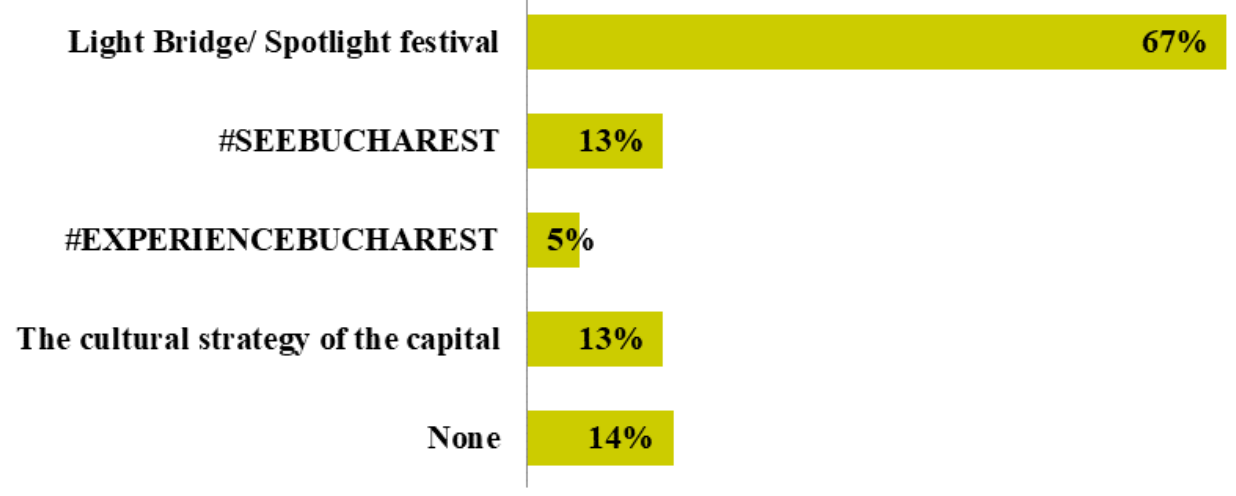

Figure 11. Promotion campaigns

Source: Authors, based on collected data

In terms of city-break holidays, $66 \%$ of respondents believe that Bucharest is an appropriate destination, while $26 \%$ consider it is not a proper place for city breaks (Figure 12). $8 \%$ of respondents did not answer the question. In the future Bucharest could be a perfect city for this particular type of holidays, because it is a mix of history and modern influences, it conserves authentic Romanian elements, it has many museums, parks etc. But in order to attract more visitors, it is necessary to improve the city's appearance, to identify solutions for traffic issues, to install more indicators that will help tourists visit the most important places in the city and of course to create better accommodation conditions.

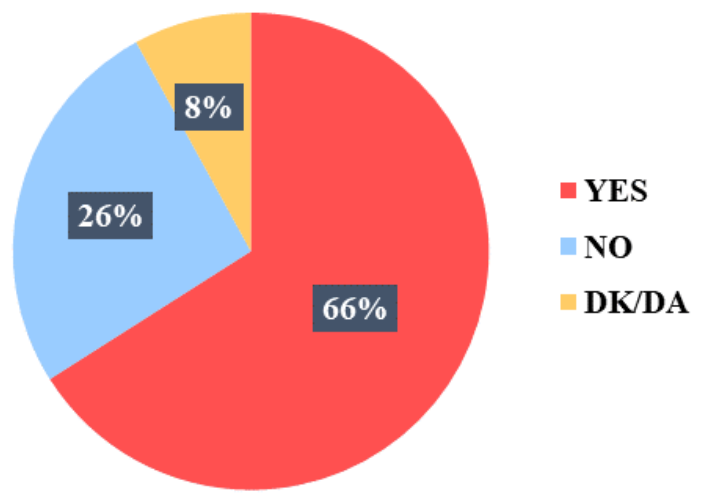

Figure 12. Bucharest as a destination for city-breaks Source: Authors, based on collected data 
Further, we wanted to find out what the respondents would be dissatisfied with if they were in the position of a tourist in Bucharest (Figure 13). The greatest factor of dissatisfaction is the degraded state of historical buildings and monuments in the city $(65 \%)$, followed by the chaotic appearance of the city (57\%), the public transport network (51\%), tourist signs $(40 \%)$, agglomeration $(39 \%)$ and hotel services (18\%). Indeed, the degraded condition of the monuments and the untidy appearance of the capital represent an obstacle in promoting the city because they create a negative image and prevent city tourism potential exploitation. Another issue concerns touristic indicators, which should be in a larger number and also be clear enough. In addition, the public transport network as well as the traffic issues in the city were considered to be a major problem requiring immediate improvement measures.

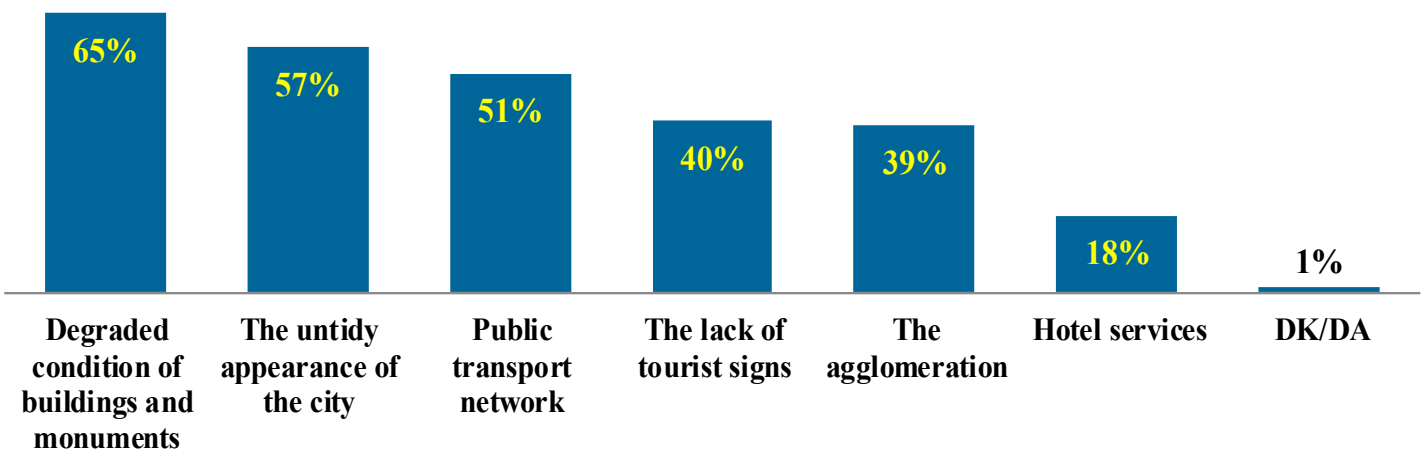

Figure 13. Bucharest's weaknesses

Source: Authors, based on collected data

\section{CONCLUSIONS}

Survey results indicate that hypothesis 1, "The city of Bucharest is promoted in an appropriate manner" is rejected because most respondents considered that several measures are needed to improve this activity, the reasons for the poor promotion being, among other things, the low involvement of public authorities, as well as the chaotic appearance of the city, the deterioration of buildings and the poor quality of public services.

Hypothesis 2 was validated because for effective promotion specialized structures were considered to be needed to guide it in the right direction and the establishment of a department in this respect was a solution alongside the development of a marketing strategy. Also, the performance of these measures will also lead to the creation of a strong urban brand.

Hypothesis 3 was also validated because $80 \%$ of respondents considered that organizing more events of different types (sports, cultural, musical, gastronomic, etc.) as well as attracting those events that are known at European or global level will increase the attractiveness of the city.

The last hypothesis that investigates Bucharest's urban brand was verified because the city is still looking for its own identity, with many problems that require quick solutions to mitigate the problems created by dissatisfied tourists and the negative image created by those problems.

In conclusion, as a result of the research carried out, we can assume that Bucharest is a city full of development opportunities, but unfortunately, they are not efficiently capitalized. We found out that the problems start from the degraded condition of the buildings and the untidy appearance of the city, continuing with management problems registered in the field of public 
services. However, with the necessary measures, the city can rise a lot, building a positive image, a strong and unique urban brand, attracting more and more tourists.

The most important thing is that decision makers to become aware of those elements that lead to differentiating the city from others and presenting them in a manner that attracts a large number of curious people. Whether it is architecture, history, lifestyle, traditions, all of these must be the focus of those who are in charge of promoting promotional activities.

Also, another important point to attract more tourists is in the quality of public services. It is very important that they meet the needs of consumers, at the required standards.

As we have seen, the poor quality of these services in the city of Bucharest is causing constant discontent, starting from the public transport network or the sanitation service. This is a major impediment to promoting the city because those who visit it notice the current situation and leave with a negative image of the city.

In order to set Bucharest city promotion on the right track it is crucial that a team of specialists guide these activities, otherwise promotion will be punctual activity, lacking long-term results.

\section{RECOMMENDATIONS}

Research findings indicate that, several measures to improve the promotion of Bucharest city are required. In this direction, the capital needs first of all a complex marketing strategy in order to have a schedule of promotional activities and to achieve long-term results, not just punctual results that have short-term effects. Also, with regard to the overall image of the city and the quality of services, it has been found that there are measures needed to improve, to combat traffic issues, to maintain the cleanliness of the city and, of course, to rehabilitate the city's buildings.

Local authorities need to be aware of the fact that the city of Bucharest has an interesting history, amazing architecture and effervescent lifestyle, aspects that should be weigh a lot in the design of a strong city brand. Also, attracting and organizing more events of different types and conferences on different themes will contribute to increasing the attractiveness of the city, because tourists who participate in different events tend to be more willing to visit the city and spend a few days or a few hours in Bucharest. After analysing the data collected with the help of the questionnaire, we found out that cultural, sporting and musical events are among the preferences of the citizens. For example, the Light Festival, recently organized in the capital, was appreciated and visited by a large number of people. However a very important aspect to be considered in terms of events and conferences has to do with their dissemination, so that information reaches as many people as possible (respondents were not knowledgeable about important city promotion projects).

Bucharest can be appreciated as a beautiful, unique city with a lot of development and promotion opportunities, but it requires some activities and measures to create a positive image able to combat the negative one created over time. By applying such measures, the capital of Romania will be able to attract more tourists, find its own identity and create a unique and strong urban brand. 


\section{REFERENCES}

Ave, G. \& Corsico, F. (1994). Urban a Tool for Cities and for Business Enterprise, a Condition for Property Development, a Challenge for Urban Planning. Urban Marketing in Europe- International Conference, Torino Incontra, Torino.

Avraham, E. \& Daugherty, D. (2009). We're known for oil. But we also have watercolours, acrylics \& pastels: Media strategies for marketing small cities and towns in Texas. Cities, 26, 331-338.

Constantinides, E. (2006). The Marketing Mix Revisited: Towards the 21st Century Marketing. Marketing Management, 22, 407-438

Dril, N., Galkin, A. \& Bibik, N. (2016). Applying city marketing as a tool to support sustainable development in small cities: case study in Ukraine. Transportation Research Procedia, 16, 46-53.

Eshuis, J., Klijn, E. H. \& Braun, E. (2014). Place marketing and citizen participation: branding as strategy to address the emotional dimension of policy making? International Review of Administrative Sciences, 80(1), 151-171.

Friedrichs, J. \& Dangschat, J. (1994). Hamburg: Culture and Competition among cities. In Biachini \& Parkinson (eds.), Cultural Policy and Urban Regeneration: The West European Experience, Manchester: Manchester University Press.

Harris, N. (1997). Cities in a global economy: Structural change and policy reactions. Urban Studies, 34(10), 1693-1703.

Harvey, D. (2012). Rebel Cities: From the Right to the City to the Urban Revolution. New York: Verso.

Kiseleva, A. M. (2017). Marketing strategy of the territory in the investment policy of the city. Strategic Management, 22(1), 22-29.

Kotler, P. (2001). Marketing Management, Harlow: Pearson Education.

Kotler, P., Nancy L. \& Eduardo R. (2002). Social Marketing: Improving the Quality of Life, California: Sage Publication.

Turok, I. \& Mykhnenko, V. (2007). The trajectories of European cities, 1960-2005. Cities, 24(3), 165-182.

Wensley, R. (2016). The basics of marketing strategy. In The marketing book (pp. 75-107). Routledge.

Wu, C. W. (2016, July). The empirical study of city marketing strategies and performance. In 2016 Global Marketing Conference at Hong Kong, 1709-1719.

Zhang, L. \& Zhao, S. X. (2009). City branding and the Olympic effect: A case study of Beijing. Cities, 26(5), 245-254. 